\title{
Chorionic gonadotrophin $\beta$ subunit mRNA but not luteinising hormone $\beta$ subunit mRNA is expressed in the pituitary of the common marmoset (Callithrix jacchus)
}

\author{
T Müller, M Simoni, E Pekel, C M Luetjens, R Chandolia'1, F Amato², R J Norman² \\ and J Gromoll \\ Institute of Reproductive Medicine of the University, Domagkstrasse 11, D-48129 Münster, Germany \\ ${ }^{1}$ Department of Gynaecology and Obstetrics, Haryana Agricultural University, Hisar-125004, India \\ ${ }^{2}$ Reproductive Medicine Unit, Department of Obstetrics and Gynaecology, The University of Adelaide, The Queen Elizabeth Hospital, Adelaide, South \\ Australia 5011, Australia
}

(Requests for offprints should be addressed to J Gromoll; Email: gromolj@uni-muenster.de)

\begin{abstract}
The pituitary gonadotrophins $\mathrm{LH}$ and FSH are responsible for regulation of gametogenesis in the testis and ovary. Chorionic gonadotrophin (CG), a third closely related glycoprotein hormone derived by gene duplication of the $L H \beta$ gene and secreted by the placenta in primates, is essential for the rescue of the corpus luteum and maintenance of pregnancy. We have recently shown that marmoset $(\mathrm{m}) \mathrm{CG} \beta \mathrm{mRNA}$ is highly expressed in the pituitary of the common marmoset (Callithrix jacchus) and that LH is less active than human CG in activating the human LH receptor lacking exon 10. To investigate further which gonadotrophin is the actual ligand of the LH receptor (LHR) of the marmoset monkey that naturally lacks exon 10, we identified and characterised the genomic organisation of the $m L H \beta$ gene and its expression. Intergenic PCR amplification of the region encompassing the $m L H \beta$ and the $m C G \beta$ genes revealed that, surprisingly, mCG $\beta$ is located $20 \mathrm{kbp}$ upstream of the $L H \beta$ gene, whereas in other species the intergenic distance is approximately $2-3 \mathrm{kbp}$. Sequence analysis of the $\mathrm{mLH} \beta$ coding region showed $70 \%$ identity to mCG $\beta$ and $90 \%$ identity to human LH $\beta$ at the amino acid level. Both gonadotrophin $\beta$ subunits are present at the genomic level, but RT-PCR of pituitary and placental total RNA using specific oligonucleotides for mCG $\beta$ and $\mathrm{mLH} \beta$ showed high expression of $\mathrm{mCG} \beta$ mRNA in both tissues, whereas LH $\beta$ was expressed neither in the pituitary nor in the placenta. Thus mLH $\beta$ mRNA is lacking in the marmoset pituitary. Immunohistochemistry of marmoset pituitaries showed that MCG was confined to the gonadotrophes, and partly co-localised in cells stained positively for FSH. Western blot analysis confirmed the presence of $\mathrm{mCG}$ in the pituitary. Northern blot analysis using $\mathrm{mCG} \beta$ as a probe displayed one transcript of $0.7 \mathrm{~kb}$ in the pituitary and detected two transcripts of $1.1 \mathrm{~kb}$ and $2 \mathrm{~kb}$ in the marmoset placenta. Our results suggest that, in the common marmoset, CG is the only gonadotrophin with luteinising function that is present in the pituitary. We postulate that, owing to an unknown mutational event in evolution, expression of $\mathrm{mLH}$ was completely abolished, and CG - which, unlike $\mathrm{LH}$, acts normally even when exon 10 is missing from the LHR - took over its function.
\end{abstract}

Journal of Molecular Endocrinology (2004) 32, 115-128

\section{Introduction}

In primates there are two pituitary gonadotrophins, luteinising hormone $(\mathrm{LH})$ and follicle-stimulating hormone $(\mathrm{FSH})$, and one gonadotrophin of placental origin, the chorionic gonadotrophin $(\mathrm{CG})$
(Hobson \& Wide 1981, Dufau 1998, Simoni et al. 1999, Weinbauer et al. 2000). The general functions of $\mathrm{LH}$ and $\mathrm{FSH}$ are the regulation of gametogenesis in the testis and ovary, whereas CG rescues the corpus luteum and maintains pregnancy. Glycoprotein hormones are heterodimers of two 
non-covalently linked subunits, of which the $\alpha$ subunit is the same for all glycoprotein hormones of a species, whereas the $\beta$ subunit determines the biological specificity for the respective receptor (Pierce \& Parsons 1981).

The genomic organisation of the LH and CG $\beta$ subunits comprises three exons separated by two introns. In the human, there are seven copies of gonadotrophin $\beta$ subunits present in a complex gene cluster, six of which represent $C G \beta$ and one $L H \beta$. Four of the $C G \beta$ copies are located in inverted pairs and are not translated (Policastro et al. 1983). The genomic structure of the $L H \beta$, in addition to the different $C G \beta$ gene copies, represents nearly accurate copies with respect to exon and intron size. $C G \beta$ evolved from a duplication of the $L H \beta$ gene, followed by a frameshift mutation in exon 3 leading to a readthrough into the 3 '-untranslated region, thereby elongating the protein by 24 amino acids, an extension known as the carboxyterminal peptide (CTP) (Fiddes \& Goodman 1980, Talmadge et al. 1984).

The exact time of appearance of $\mathrm{CG}$ in primates is unknown, but the duplication of the $L H \beta$ gene should be approximately 30-40 million years ago (Kumar \& Hedges 1998, Maston \& Ruvolo 2002). Although trace amounts of genuine human (h) GG have been demonstrated in the human pituitary (Birken et al. 1996), LH is the only luteinising gonadotrophin present in physiologically relevant amounts in the pituitary of mammals, with the exception of horses and guinea pigs, which have a single copy $L H / C G \beta$ gene expressed in the pituitary and placenta (Sherman et al. 1992, 2001). Furthermore, the primate genome usually bears only one copy of $L H \beta$, but one or more copies of $C G \beta$ (Sherman et al. 2001, Maston \& Ruvolo 2002). Sequence information for many primate gonadotrophins is available today (Maston \& Ruvolo 2002), mostly from Old World monkeys (Schmidt et al. 1999). In some species, such as the marmoset monkey (Callithrix jacchus), an important animal model for human reproduction, CG has already been characterised and cloned (Hobson \& Wide 1981, Simula et al. 1995) from the trophoblast cells of the placenta, whereas the sequence and pattern of expression of the $L H \beta$ subunit remain unknown.

Findings from our group raised interest in marmoset (m) LH. In the human, the LH receptor (LHR), mediating the action of both $\mathrm{LH}$ and $\mathrm{GG}$, shows considerable differences in signal trans- duction in vivo and in vitro if exon 10, encoding part of the extracellular hinge region, is deleted (Gromoll et al. 2000, Müller et al. 2003). We showed that the hLHR lacking exon 10 could bind normally both LH and CG, but a 30-fold greater dose of $\mathrm{LH}$ was needed to induce cAMP formation comparable to that obtained by hCG (Müller et al. 2003). As this was not the result of receptor desensitisation or permanent activation of the $G_{i}$ protein, one possible explanation could be the different structure of the gonadotrophins, e.g. the CTP.

The LHR of the marmoset monkey naturally lacks exon 10 (Zhang et al. 1997), as is the case for other members of the Platyrrhini lineage (Gromoll et al. 2003). This peculiar, naturally occurring LHR which we named LHR type II, encompasses exon 10 at the genomic level, but is absent at the transcriptional level. Because of the high homology $(94 \%$ identity at the nucleotide level) between hLHR and mLHR (Zhang et al. 1998), the question emerges as to how the marmoset monkey could maintain normal gonadal function if LH is not working correctly on an LHR lacking exon 10. In previous experiments we detected a surprisingly high expression of mCG $\beta$ mRNA by RT-PGR in the marmoset pituitary (Gromoll et al. 2003). This unexpected finding suggested that $\mathrm{mCG}$, and not $\mathrm{mLH}$, could be the relevant pituitary gonadotrophin in the marmoset. In the present study we characterised both genes and demonstrate expression of $\mathrm{mCG}$ only in the pituitary.

\section{Materials and methods}

\section{PCR, RT-PCR and long template intergenic PCR}

PCR generally followed 30 cycles with annealing temperatures from $55^{\circ} \mathrm{C}$ to $78{ }^{\circ} \mathrm{C}$ for $40 \mathrm{~s}$ (depending on the primers used) and elongation time of $72{ }^{\circ} \mathrm{C}$ for $2 \mathrm{~min}$. PCR products were resolved on a $1.5 \%$ agarose gel and the DNA bands were isolated, purified by a DNA purification kit (Roche) and cloned into pGEM T-easy vector (Stratagene, La Jolla, CA, USA). Both strands of denatured double-stranded DNA were sequenced with a commercial kit (Amersham) using T7 and T3 primers and the dideoxynucleotide termination method. 


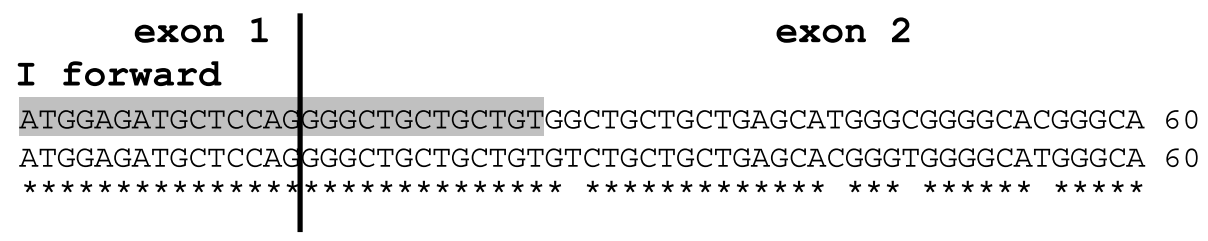

LH $\beta$ Callithrix $j$. TCCAGGGAGCCGCTGCGGCCACTGTGCCGCCCCATCAATGCCACCCTGGCTGCCGAGAAG 120 CG $\beta$ Callithrix $j$. TCCAAGGAGCCACTTCGGCCACTGTGTCGCCCCGTCAATGCCATCCTGGCTGCTGAGAAG 120

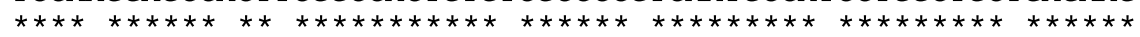

\section{VI forward}

LH $\beta$ Callithrix j. GAGGCCTGCCCCGTGTGCATCACCGTCAACACCACCATCTGTGCCGGCTACTGCCCCACC 180

CG $\beta$ Callithrix $j$. GAGGGCTGCCCTGTGTGTGTCGCCTTTAACACCACCATCTGTGCCGGCTACTGCTCCAGC 180

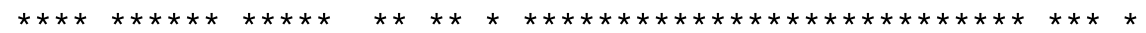

exon 3

LH Callithrix j. ATGATGGCGGGTGCTGCAGGCGGTCCTGCCGCCAGTGCCCCAGGTGGTATGCAACTACCG 240

CG $\beta$ Callithrix $j$. ATAATGACGGGTGCTGCAGACCATCTTACCGCCCTTACCCCAGTCGGTGTGCAACTACCA 240



LH $\beta$ Callithrix j. CGAGGTGCGCTTCGAGTCCATCCGGCTCCCTGGCTGCCCGCCTGGCGTGGACCCCGTGGT 300 CG $\beta$ Callithrix j. CGAGCTGCGCTTCACCTCTGTCCGGCTCCCTGGCTGTCGGCCCGGCGTGGATCCCGTAGT 300 $\star * * * \quad * * * * * * * * \quad * * \quad * * * * * * * * * * * * * * * * \quad * \quad * * * \quad * * * * * * * * \quad * * * * * * *$

\section{III forward, IV reverse}

LH $\beta$ Callithrix j. CTCCGTTCCCGTGGCTCTCAGCTGTTGCTGTGGACCCTGCCGCCGCAGCACCTCTGACTG 360 CG $\beta$ Callithrix $j$. TTCCATGCCCGTGGCTCTCAGCTGTCGCTGTGGTCTCTGCCGCAGAAGCTATTCTGACTG 360

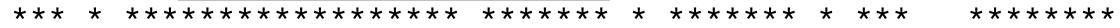

LH $\beta$ Callithrix j. TGGGGGTCCCAAAGACCACCCCTTGACCTGTGACCACCCCCAACTCTCAGGCCTCCTCTT 420 CG $\beta$ Callithrix $j$. CGGGAGTCTCAGGAACGAGCCCTTGGGCTGTGACTACTCC-ACCTTCCAGGACTC---TT 416 $* * * * * * * \quad * * * * * * * * * * * * * * * * * * * * * * * * * * * * * \quad * *$

\section{$\mathrm{V}$ reverse}

LH $\beta$ Callithrix j. CCTCTAAagaccctccccgcagccttccaagtccatcccgactcctggagcccttcgaca 480 CG $\beta$ Callithrix j. CCTCTAAGGACCCTCCCCGCAACCTTACAAGTCCATCCCAACTCCTGGAGCCAGCAGACC 476

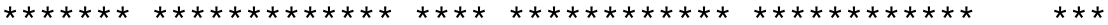

\section{II reverse}

LH $\beta$ Callithrix j. ccccgatcctcccacaataaaggcttctcaatccgc 516 CG Callithrix j. CTCCATTAGTCCCACAATAAaggettctcaatccgc 512

Figure 1 Nucleotide sequence comparison of $m L H \beta$ and $m C G \beta$ of the common marmoset Callithrix jacchus (non-translated region of $m L H \beta$ is given in small letters). Oligonucleotide pairs indicated by grey boxes used in the different amplifications: I forward/II reverse, amplification of $m C G \beta$ in RT-PCR and DNA; III forward/IV reverse, bidirectional long template PCR from DNA; III forward/II reverse, amplification of endpiece of $m C G \beta$ from bidirectional long template PCR; III forward/V reverse, amplification of endpiece of $m L H \beta$ from bidirectional long template PCR; I forward/IV reverse, amplification of $m L H \beta$ from bidirectional long template PCR; VI/VII forward/IV reverse, specific amplification of $m L H \beta$ from RNA and DNA. Vertical lines give the exon boundaries.

Long template, intergenic PCR was performed using an Expand Long Template PCR System kit (Roche) with oligonucleotides located in the middle of exon 3 designed from a interspecies comparison (Fig. 1). The reactions were carried out according to the manufacturer's recommendations 
and were run in a Robocycler 96 PGR machine (Stratagene).

The reverse transcriptase (RT) reaction was carried out with $1 \mu \mathrm{g}$ RNA as template for murine myeloma virus RT (Promega) primed with $1 \mathrm{ng}$ reverse primer. PCR using different primer combinations (indicated in Fig. 1) was performed with $5 \mu \mathrm{l}$ RT product using $0.2 \mathrm{U}$ Thermophilus aquaticus DNA polymerase (Qiagen) in a Hybaid PCR Express (Hybaid, Heidelberg, Germany) or Stratagene Robocycler 96 (Stratagene).

Marmoset monkey DNA was obtained from blood samples of one male and two female animals, using a commercial kit (FlexiGene DNA 50, Qiagen), and stored at $4{ }^{\circ} \mathrm{C}$. Total RNA was isolated from five (two males and three females) healthy monkey pituitaries and two placentas, using a commercial kit (Ultraspec, Biotex Laboratories, Houston, TX, USA).

The design of the oligonucleotides was based on preliminary results from our group (Gromoll et al. 2003) and others (Sherman et al. 2001, Maston \& Ruvolo 2002) assuming high sequence homology with, or diversity from, other monkey gonadotrophin subunits respectively. The oligonucleotides covered a variety of positions between the $5^{\prime}$ - and the $3^{\prime}$ - ends of the monkey $L H \beta$ and $C G \beta$ coding sequences and genomic DNA; they are listed in Fig. 1.

\section{Northern blot hybridisation}

Fifteen micrograms total RNA from pituitary, liver, ovary and placenta of a marmoset monkey were run on a $1 \%$ agarose-formaldehyde gel and then transferred overnight to a nylon membrane (Hybond-N, Amersham) for northern hybridisation. RNA was fixed on the membrane by irradiation with UV light at $302 \mathrm{~nm}$ for $1 \mathrm{~min}$. ${ }^{32} \mathrm{P}$-Labelled cDNA probes were prepared from an EcoRI-digested plasmid containing hCG $\beta$ cDNA. Hybridisation was performed in glass tubes containing the hybridisation solution $(5 \times \mathrm{SSPE}, \quad 2 \times$ Denhardts, $50 \%$ formaldehyde, $100 \mu \mathrm{g} / \mathrm{ml}$ denatured salmon sperm DNA, $1 \%$ SDS, $5 \times 10^{6}$ c.p.m. $/ \mu$ l labelled probe) at $68{ }^{\circ} \mathrm{C}$ overnight. The membrane was washed three times with $0 \cdot 1 \times \mathrm{SSC}$ containing $1 \% \quad \mathrm{SDS}$ at $68{ }^{\circ} \mathrm{C}$ for $30 \mathrm{~min}$, followed by exposure on X-ray film (Kodak) at $-80^{\circ} \mathrm{C}$ using an intensifying screen (Amersham).

\section{Immunohistochemistry}

Sectons $4 \mu \mathrm{m}$ thick were cut from Bouin-fixed, paraffin-embedded specimens of pituitaries of three male marmoset monkeys. After the sections had been deparaffinised and rehydrated, primary antibody against hCG (polyclonal anti-human CG (AHP 536, Serotec, Düsseldorf, Germany) with crossreactivity $<1 \%$ with $\mathrm{LH}$ and $<0.3 \%$ with FSH) was applied for $30 \mathrm{~min}$ at room temperature in blocking buffer. Controls were performed by omitting the primary antibody. The available antibody against mCG (R64-050396) showed binding only in the western blots and did not work on tissue sections, presumably because of the paraffin embedding procedure; for histological sections we therefore used the human hCG antibody. To visualise FSH in the pituitary gland, a primary antibody against human FSH (0373, Immunotech, Marseille, France) was utilized. After washing, slides were incubated with biotin-labelled goat anti-rabbit immunoglobulins and then with streptavidin conjugated to horseradish peroxidase for $15 \mathrm{~min}$ at room temperature, followed by incubation with diaminobenzidine substrate solution for $15-30 \mathrm{~min}$. The staining reaction was stopped by washing in $1 \times$ trisbuffered-saline (TBS). The slides were counterstained with haematoxylin for $10 \mathrm{~s}$ and mounted under coverslips with Dako Faramount medium (Dako Diagnostika, Hamburg, Germany) before observation using an Axioskop microscope (Carl Zeiss, Jena, Germany) at different magnifications $(10 \times$ and $20 \times$ objectives $)$. Digital images from equal exposure times were obtained with a CCD camera (Axiocam, Zeiss) controlled by Axiovision image software (Carl Zeiss).

\section{Immunofluorescence staining}

Immunofluorescence staining for $\mathrm{mCG}$ was performed with either the specific mCG (R64) primary antibody or the hCG antibody on $\mathrm{CHO}$ cells stably expressing recombinant mCG (Amato et al. 1998). The cells were grown on Falcon culture slides (Becton Dickinson Labware, Le Pont de Claix, France) overnight and fixed for $30 \mathrm{~min}$ with $4 \%$ paraformaldehyde. After a blocking step with 5\% BSA and $0 \cdot 1 \%$ Triton X-100, the mCG antibody together with $1 \%$ BSA and $0 \cdot 1 \%$ Triton $\mathrm{X}-100$ was applied. The rabbit polyclonal $\mathrm{mCG}$ antibody 
was detected with an anti-rabbit antibody conjugated with TRITG (T-5268, Sigma). All incubations were performed at room temperature, for $2 \mathrm{~h}$ with the primary antibody and $1 \mathrm{~h}$ with the secondary antibody. The cells were counterstained with $1 \mu \mathrm{g} / \mathrm{ml} \mathrm{4}^{\prime}$-6-diamidino-2-phenylindole (DAPI, Sigma) for $5 \mathrm{~min}$. Both fluorescent dyes were excited with the appropriate filter set on an Axioskop (Carl Zeiss, Jena, Germany) at a magnification of $200 \times$. Control cells, without the primary antibody, were negative for the TRITC fluorescent signal. Images were taken with the Axiocam controlled by Axiovision software.

\section{Western blot}

Proteins resolved by $12 \%$ SDS-PAGE, under reducing conditions, were transferred to a nitrocellulose membrane $(0.4 \mu \mathrm{m})$ at $100 \mathrm{~mA}$ for $1 \mathrm{~h}$. The membrane was incubated with $5 \%$ low-fat dried milk in PBS (pH 7.4) with $150 \mathrm{mM} \mathrm{NaCl}$ and $0 \cdot 1 \%$ Tween 20 for $1 \mathrm{~h}$. A further incubation was performed with the polyclonal mCG antibody R64 (diluted 1:2000) (Amato et al. 1998) for $1 \mathrm{~h}$ at room temperature, followed by incubation with antirabbit IgG horseradish peroxidase conjugate (Sigma; diluted 1:20 000) for a further $1 \mathrm{~h}$. After each incubation, membranes were washed three times with the PBS-Tween 20 solution. Detection was achieved with enhanced chemiluminescence using the SuperSignal West Pico Chemiluminescent Substrate Kit from Pierce (Bonn, Germany).

\section{Results}

\section{Search for LH $\beta$ mRNA expression in the pituitary}

Using oligonucleotides published previously by Simula et al. (1995) and suitable for amplification of mCG $\beta$ mRNA from placental tissue (Fig. 1, I forward/II reverse), we were able to amplify mCG $\beta$ mRNA from the pituitary of the common marmoset (Gromoll et al. 2003). However, using this primer combination, no clone containing nucleotide sequence reminiscent of $L H \beta$ was found. In an additional approach we used 12 oligonucleotides (not shown) directed to consensus sequences derived from sequence comparisons of the known $L H \beta$ genes from other primates to amplify the mLH $\beta$ mRNA from the pituitary (Maston \&
Ruvolo 2002). The amplicons obtained were further analysed by either single-stranded conformation polymorphism or direct sequencing to distinguish $L H \beta$ from $C G \beta$. Again, no mLH $\beta$ mRNA could be detected. Thus the following two options emerged: i) the sequence of the $L H \beta$ gene is very different from that of the $C G \beta$ gene in the marmoset, thereby hindering correct PCR amplification, or ii) the $L H \beta$ gene is not expressed.

\section{Identification and characterization of the marmoset $L H \beta$ gene}

The organization of $m L H \beta$ gene was analysed using genomic DNA. With two oligonucleotides (Fig. 1, III forward/IV reverse) directed to one $L H \beta / C G \beta$ consensus sequence from different species, we attempted to amplify the genomic region between the $L H \beta$ and $C G \beta$ genes. Such a strategy would result in amplification only when two $(L H \beta$ and $C G \beta)$ or more highly homologous genes are present. Furthermore, it could give important information on the orientation of the genes. If more copies of the $m C G \beta$ gene were present, it is likely that differences in the intronic sizes between the genes would produce more than one amplification product. A similar amplification of several bands representing different gene copies has previously been shown for the $h C G \beta$ and $h L H \beta$ gene cluster, where the intergenic distance is approximately 3 kbp (Maston \& Ruvolo 2002). With long template PCR techniques using marmoset genomic DNA, we amplified one large amplicon of approximately $20 \mathrm{kbp}$ (Fig. 2b, R1). The amplicon was purified and used as a template for the subsequent PGR reactions to confirm whether it contained the $m C G \beta$ and $m L H \beta$ genes.

By using primer combinations capable of amplifying either the $3^{\prime}$ or the $5^{\prime}$ part of the presumed genes and subsequent cloning and sequencing of the amplicons, we gathered insights into the organisation and the sequence of the genes. With the primer combination III forward/II reverse we were able to amplify the $3^{\prime}$ portion of the $C G \beta$ gene with its characteristic mutation giving rise to the translation of the CTP. With the primer combination I forward/IV reverse, we obtained a $900 \mathrm{bp}$ product with sequences significantly different from those of the mCG $\beta$ cDNA (Fig. 1). This part contains exons 1, 2 and part of exon 3 of the $L H \beta$ gene (Fig. 2b, R2). 
(a)

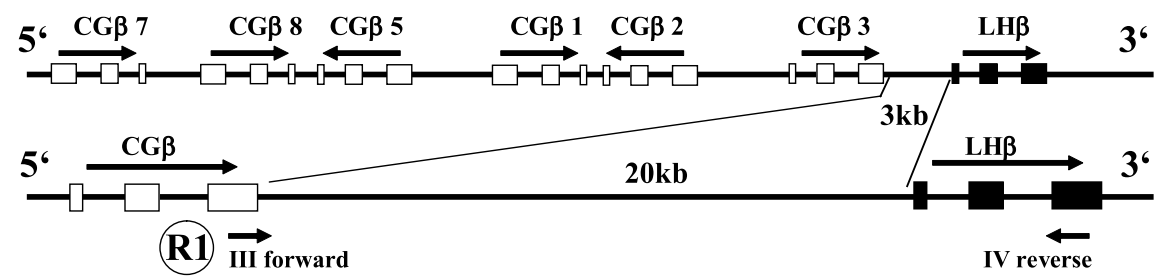

(c)



Figure 2 Strategy to detect marmoset $\mathrm{LH} \beta$ at the genomic level. (a) Schematic organisation of $h L H \beta / h C G \beta$ cluster. (b) Situation in the marmoset: $m C G \beta$ is separated from $m L H \beta$ by a $20 \mathrm{~kb}$ insertion, as revealed by intergenic PCR reaction (R1) (oligonucleotide pair: III forward/IV reverse). (c) Magnification of (b): fragment 1 located at the $5^{\prime}$ end with 163 bases matched $100 \%$ of the mCG sequence, whereas a 900 base fragment at the $3^{\prime}$ end showed just $81 \%$ identity to $m C G$ but $93 \%$ to $h L H(R 2)$. Amplification of the $3^{\prime}$ end of $m L H \beta$ was performed with specific oligonucleotide ( $\mathrm{VI}$ forward/ $\mathrm{V}$ reverse) designed from sequence analysis of fragment 2 (R3). The corresponding exon and intron sizes for the $m L H \beta$ gene are indicated in bp numbers.

\section{Unilateral specific PCR}

The genomic approach using one nucleotide sequence to amplify two genes left the 3 ' part of the $L H \beta$ gene unidentified (Fig. 2b). The missing $3^{\prime}$ part of the $L H \beta$ gene was obtained by unilateral specific PGR. For this we designed specific oligonucleotides (VI forward, VII forward) based on the obtained $L H \beta$ sequences, which were used in conjunction with the less specific $\mathrm{V}$ reverse primer to amplify the missing $3^{\prime}$ region (Fig. 1). Two amplicons of 900 and $350 \mathrm{bp}$ respectively were obtained from genomic DNA, of which the last 160 bases contained the remaining portion of the $L H \beta$ gene (Fig. 2c, R3). Upon cloning and sequence analysis, we could identify sequences completing the $L H \beta$ gene of the common marmoset.

\section{Sequence analysis}

The $L H \beta$ gene of the common marmoset consists of three exons and two introns (Fig. 2). Exon 1 encodes $15 \mathrm{bp}$, exon $2168 \mathrm{bp}$ and exon $3276 \mathrm{bp}$; the two corresponding introns cover $410 \mathrm{bp}$ and 229 bp respectively. The exon and intron sizes are in good agreement with other $L H \beta$ genes (Jameson et al. 1984, Talmadge et al. 1984). The typical splice sites are preserved in the $L H \beta$ gene (not shown). The deduced open reading frame consists of $426 \mathrm{bp}$.

Interestingly, a CTC triplet coding for leucine is lacking in the mCG $\beta$ subunit cDNA, but is present in the $L H \beta$ gene of the marmoset and other species. The hallmark of all $L H \beta$ genes, the presence of an adenosine at position 400 leading to a translational stop codon at position 426, could be shown. $\mathcal{N}$-Linked glycosylation at position Asn 30 is possible, and it is likely that $\mathrm{mLH}$ would also be glycosylated at position Asn 13, where mCG has lost its glycosylation recognition motif (N-A-T) (Fig. 3). All conservative cysteines were present, similar to human gonadotrophins and mCG (Fig. 3). At the amino acid level, LH $\beta$ has an identity of $89 \%$ to $\mathrm{hLH} \beta$ and $78 \%$ to $\mathrm{hCG}$, whereas identity to mCG $\beta$ reached only $70 \%$. The signal peptide region of $\mathrm{mLH}$ corresponds to that of $\mathrm{hLH}$.

\section{Dendrogram}

Using CLUSTAL W software (European Bioinformatics Institute, Cambridge, UK) a dendrogram was deduced showing the homologies of $L H \beta$ and $C G \beta$ genes from several primate species, including humans, covering all different important 

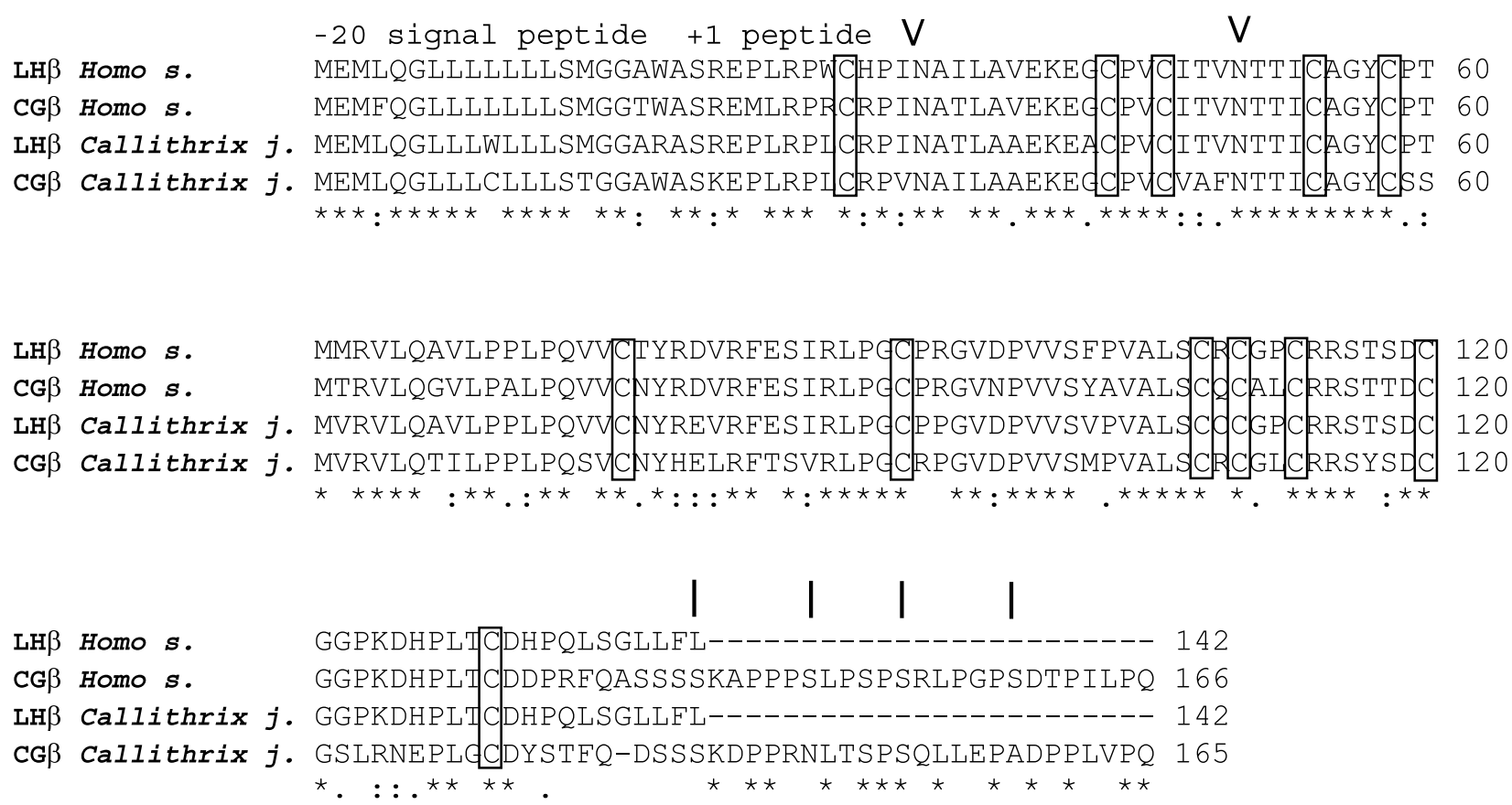

Figure 3 Multiple sequence analysis of amino acids of marmoset monkey $L H \beta$ (based on genomic information), $m C G \beta, h L H \beta$ and $h C G \beta$ subunits. $m L H \beta$ shows $89 \%$ identity to $h L H \beta$ and $78 \%$ to $h C G \beta$, but only $70 \%$ to $m C G \beta$ at the amino acid level. $N$-Linked glycosylation sites are represented by $\vee$, I symbols represent putative $O$-linked carbohydrates, not present in LH. The 12 typically conserved cysteines in gonadotrophins are boxed.

lineages (Fig. 4). We analysed in detail the $L H \beta$ and $C G \beta$ sequences from the New World monkey Callithrix jacchus $(m)$, the Old World monkey Macaca fascicularis (cyn), the great ape Pongo pygmaeus and the human. The $L H \beta$ genes and the $C G \beta$ genes from human and the chimpanzee were closely related, whereas the New World and Old World monkeys seemed to form a separate group with respect to the $L H \beta$ genes (Fig. 4). Interestingly, both $C G \beta$ genes showed markedly reduced homology to the $h L H \beta$ or $h C G \beta$ genes: $h L H$ compared with cyn $C G 84 \%$ and $h C G$ compared with cynCG $81 \%$ identity for $M$. fascicularis; $h L H$ compared with $m C G 69 \%$ and $h C G$ compared with $m C G 66 \%$ for C. jacchus (Fig. 4). Thus the $m C G \beta$ gene is the most divergent nucleotide sequence among the $L H \beta / C G \beta$ gene family (Fig. 4).

\section{Expression analysis of the $\mathrm{mLH} \beta$ and $C G \beta$ mRNA in pituitary and placenta}

Using the new sequence information obtained from the genomic cloning of the $m L H \beta$ gene, we investigated the expression of the $L H \beta$ gene in the pituitary. Using primer combinations specific either to LH $\beta$ or mCG $\beta$, we performed RT-PGR of total RNA preparations from the pituitary or the placenta (Fig. 5). According to the sequence data obtained and the genomic organization of the genes, a $333 \mathrm{bp}$ fragment is to be expected for LH $\beta /$ CG $\beta$ RNA in the pituitary and placenta when using a primer combination capable of amplifying both genes (I forward/IV reverse) and an $L H \beta$ gene-specific band of 205 bases (VI forward/IV reverse) is expected when using the primer combination VI forward/V reverse (Fig. 1). Genomic DNA served as template to confirm PCR fidelity of the primer combinations used. As expected, we observed an amplicon of approximately $333 \mathrm{bp}$ for the potentially simultaneous amplification of $C G \beta / L H \beta$ from pituitary RNA; however, no product was obtained when the $L H \beta$-specific primer was used (Fig. 5). Thus $L H \beta$ is not transcribed in the pituitary. The amplicon from the first RT-PGR (lane 1) corresponded completely to $\mathrm{mCG} \beta$ cDNA revealed by DNA sequencing (data not shown). A similar picture was obtained in the placenta, with $m C G \beta$ being the only gene expressed. The fragments obtained from genomic DNA correspond to the fragment length expected 
(a)

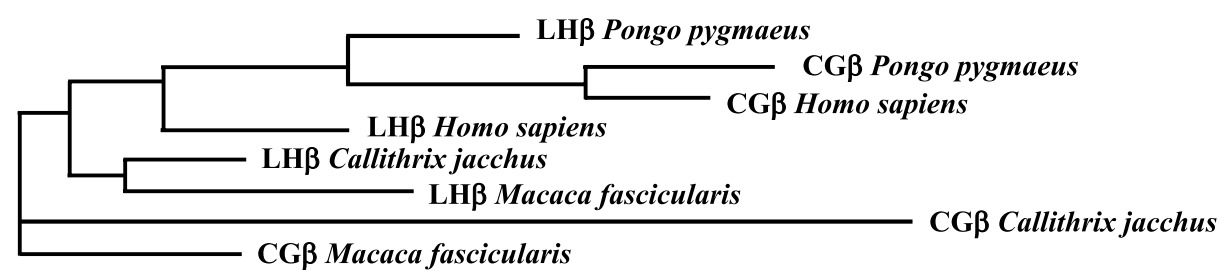

(b)

\begin{tabular}{|c|c|c|c|c|c|c|c|}
\hline \begin{tabular}{|l} 
Homology \\
AA's (\%) \\
\end{tabular} & \begin{tabular}{|l} 
Pongo $p$. \\
LH $\beta$
\end{tabular} & $\begin{array}{l}\text { Pongo p. } \\
\text { CG } \beta\end{array}$ & $\begin{array}{l}\text { Callithrix } j . \\
\text { LH } \beta\end{array}$ & \begin{tabular}{|l} 
Callithrix $j$. \\
CG $\beta$
\end{tabular} & $\begin{array}{l}\text { Homo s. } \\
\text { CG } \beta\end{array}$ & \begin{tabular}{|l} 
Homo s. \\
LH $\beta$
\end{tabular} & \begin{tabular}{|l} 
Macacaf. \\
CG $\beta$
\end{tabular} \\
\hline $\begin{array}{l}\text { Macacaf. } \\
\text { LH } \beta\end{array}$ & 81 & 68 & 90 & 68 & 73 & 87 & 85 \\
\hline $\begin{array}{l}\text { Macacaf. } \\
\text { CG } \beta\end{array}$ & 79 & 79 & 91 & 73 & 81 & 84 & \\
\hline $\begin{array}{l}\text { Homos. } \\
\text { LH } \beta\end{array}$ & 88 & 77 & 90 & 69 & 81 & & \\
\hline $\begin{array}{l}\text { Homos. } \\
\text { CG } \beta\end{array}$ & 84 & 92 & 78 & 66 & & & \\
\hline $\begin{array}{l}\text { Callithrix j. } \\
\mathrm{CG} \beta \\
\end{array}$ & 66 & 67 & 70 & & & & \\
\hline $\begin{array}{l}\text { Pongo } p \text {. } \\
\text { CG } \beta\end{array}$ & 88 & & & & & & \\
\hline
\end{tabular}

Figure 4 (a) Dendrogram of LH $\beta$ and CG $\beta$ subunit genes from different primates, derived using CLUSTAL W software. (b) Percentage of amino acid (AA) identities between the different species and subunits.

for the amplification of portions from the $L H \beta$ or $C G \beta$ gene. The larger size observed is attributable to intronic sequences, as the primers were designed to cover exons 2 and 3.

\section{Northern blot hybridisation}

The expression of mCG $\beta$ mRNA in different tissues was analysed by Northern blot hybridisation using the complete mCG $\beta$ cDNA as a probe (Fig. 6). mCG $\beta$ mRNA was specifically expressed in the pituitary and placenta of the marmoset monkey, whereas other tissues, such as liver or ovary, were negative. The pituitary transcript size was approximately $0.7 \mathrm{~kb}$, whereas two transcripts of $1 \cdot 1 \mathrm{~kb}$ and $2 \mathrm{~kb}$ were detected in the placenta (Fig. 6).

\section{Immunohistochemistry}

Using an antibody against hCG, specific staining of $\mathrm{CG}$ in the marmoset pituitary could be demonstrated (Fig. 7A). The GG-positive cells were distributed randomly throughout the adult pituitary gland, showing that approximately $25 \%$ of the cells produce CG. The concentration of $\mathrm{CG}$ in the cytoplasm of these cells showed equal staining, giving the impression that all CG-producing cells could release a similar amount of $\mathrm{CG}$. The polyclonal $\mathrm{mGG}$ antibody used did not work in paraffin-embedded sections of marmoset tissues; however, we obtained specific signals in cell cultures stably expressing mGG (Fig. 7D, E). Similar signals were obtained in these cell cultures using the hCG antibody (data not shown). Thus detection of $\mathrm{mCG}$ using the $\mathrm{mCG}$ antibody is specific. Some GG-producing pituitary cells were also positive for expression of FSH protein (not shown). This FSH expression showed that more cells produce FSH (Fig. 7B) than produce CG; three types of cells were found, some producing only $\mathrm{CG}$, a low number producing both $\mathrm{CG}$ and $\mathrm{FSH}$, and a larger group of cells producing solely FSH.

\section{Western blot}

A western blot using the polyclonal $\mathrm{mCG}$ antibody was performed using protein extracts from $\mathrm{CHO}$ cells stably expressing the recombinant mCG (see above) and from rat, cynomolgus and marmoset 


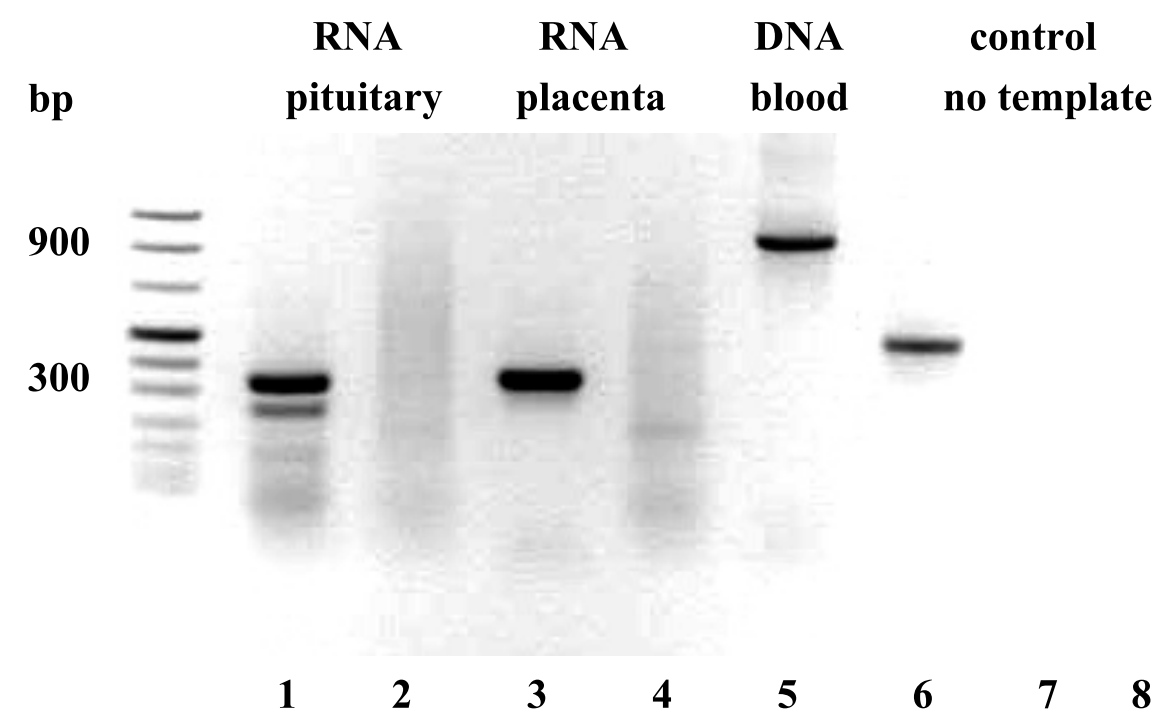

Figure 5 RT-PCR from marmoset pituitary and placenta, demonstrating that only mCG $\beta$ is expressed. Amplification of marmoset CG $\beta$ obtained from placenta, pituitary and genomic DNA isolated from blood samples. Lanes 1, 3, 5: I forward/IV reverse amplifies both CG $\beta$ and LH $\beta$. Lanes 2, 4, 6: VI forward/IV reverse amplifies LH $\beta$ exclusively. Lanes 7, 8: Negative controls. A 333 base fragment was found for both LH and CG at the mRNA level (lane 1 and 3). LH $\beta$ mRNA would yield a 205 bp fragment (lane 2 and 4), but was not amplified. At the genomic DNA level, mCG $\beta$ and $\mathrm{mLH} \beta$ produced a fragment of $900 \mathrm{bp}$ sequences (lane 5); $\mathrm{LH} \beta$-specific amplification gave rise to a $550 \mathrm{bp}$ fragment (lane 6); both fragments are considerably larger than RT-PCR fragments, which is the result of intronic sequences. For the genomic amplification, a shorter forward primer I, corresponding to the boundaries of exon 1, was used (Fig. 1). RT-PCR was independently repeated with RNA from three pituitaries with different PCR conditions.

monkey pituitaries (Fig. 8). Double bands, presumably corresponding to the $\beta$ subunit and probably exhibiting different glycosylation patterns, were detectable in both the cell extracts from the $\mathrm{CHO}$ cells (Fig. 8, lanes 1 and 5) and the pituitary from the marmoset monkey (Fig. 8, lane 3). The bands in the pituitary were shifted towards a greater molecular weight, which might be a reflection of different glycosylation patterns. No bands were visible in the pituitaries of rat and cynomolgus monkey (Fig. 8, lanes 2 and 4), indicating the lack of expression of $\mathrm{CG}$ and also that this antibody did not specifically bind to LH in those animals.

\section{Discussion}

The marmoset monkey belonging to the Platyrrhini lineage is one of the most important animal models in clinical and toxicological research around the world. Its small size and easy reproduction in captivity are considered an advantage for studies in non-human primates (Smith et al. 2001, Zuehlke \& Weinbauer 2003). Marmoset placental CG $\beta$ has been the subject of several studies in the past (Hobson \& Wide 1981, Saunders et al. 1987, Rosenbusch et al. 1994, Simula et al. 1995), whereas the genomic sequence of $\mathrm{mLH}$ was unknown. In the present work we used intergenic PCR to demonstrate the existence of both $m C G \beta$ and $m L H \beta$ subunit genes, separated by an intronic sequence of approximately $20 \mathrm{~kb}$, with $C G \beta$ placed $5^{\prime}$ of the $L H \beta$ gene. Sequence analysis of the coding region and deduced amino acids of $m L H \beta$ compared with $m C G \beta$ showed $70 \%$ identity, compared with $81 \%$ in the human. $m L H \beta$ showed $90 \%$ identity to $h L H \beta$ at the amino acid level.

We were able to confirm that mCG $\beta$ is highly expressed in the pituitary (Gromoll et al. 2003), but were unable to detect the expression of $\mathrm{LH} \beta$ mRNA. Pituitary expression of trace amounts of 


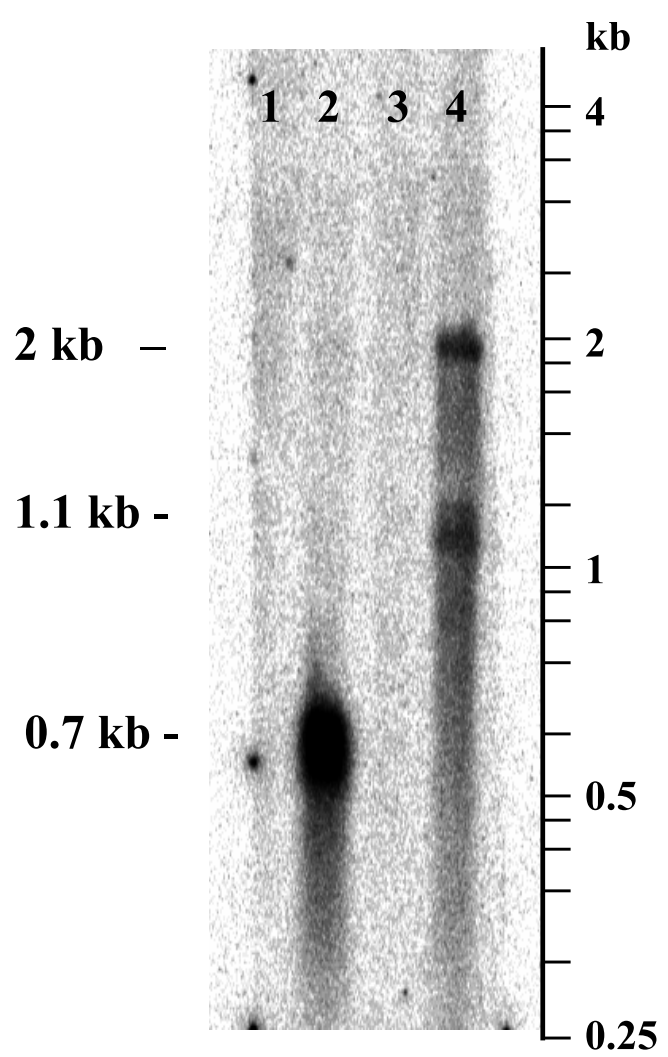

Figure 6 Northern hybridisation of marmoset CG $\beta$ mRNA. Lane 1: ovary; lane 2: pituitary; lane 3: liver; lane 4: placenta. In the pituitary, one specific band of $0.7 \mathrm{~kb}$ is visible, whereas in the placenta two bands of $1.1 \mathrm{~kb}$ and $2 \mathrm{~kb}$ are detectable.

hCG is also found in the human. The isolation and characterisation of hCG from the human pituitary showed that it bears a glycosylation pattern that makes it more similar to LH than to placental hCG (Birken et al. 1996). However, no physiological role for pituitary hCG is known. In the marmoset, we observed the opposite phenomenon: $\mathrm{CG}$ is the major luteinising gonadotropin in the pituitary gland. The fact that expression of $\mathrm{LH} \beta$ mRNA is lacking in the marmoset pituitary could be the result either of a lack of transcription factors involved in the regulation of $m L H \beta$, or of genetic alterations. We did not find any unusual genetic changes within the exon-intron structure of the $L H \beta$ gene that prevented gene expression; however, we noticed an unusual extension of the intergenic region between the $m C G \beta$ and $m L H \beta$ genes. In other primates, including the human, the intergenic distance is approximately $2-3 \mathrm{kbp}$, but the marmoset displays a $20 \mathrm{kbp}$ region. Such an expansion might be the result of an insertion - for example retrotransposition of long interspersed nuclear element (LINE) elements, which are known to be responsible for gene silencing. In the cotton tamarin, such a retrotransposon has led to the silencing of the semenogelin II gene and subsequently to its elimination from the genome (Lundwall \& Olsson 2001). Future studies are needed to reveal the structure and sequences of the large intergenic region and the mechanism underlying the inactivation of $\mathrm{LH} \beta$ in the marmoset.

The transcription of the $m C G \beta$ gene is highly tissue specific and yielded two different transcript patterns for the pituitary and the placenta. The $0.7 \mathrm{~kb}$ transcript in the pituitary and the $1.1 \mathrm{~kb}$ in the placenta are in good agreement with transcript sizes described in other species (Fiddes \& Goodman 1980, Gromoll et al. 1993), whereas the existence of the $2 \mathrm{~kb}$ transcript might be attributable to a hitherto unknown new transcriptional start site in the $m C G \beta$ gene. In the horse, the $L H \beta$ gene is expressed both in the pituitary and in the placenta, using the same transcriptional start site, which is homologous to that of the human $L H \beta$ gene (Sherman et al. 1992), giving rise to identical transcript sizes. In a functioning CG $\beta / \mathrm{LH} \beta$ system it is assumed that, during evolution, changes within the promoter regions of $C G \beta$ genes have led to the placenta-specific expression, and the usage of a novel transcriptional start site for the $C G \beta$ gene yields transcripts of $1.1 \mathrm{~kb}$ (Jameson et al. 1984, Hollenberg et al. 1994). In the marmoset, the situation is very different. The various transcripts observed must be derived from the same gene. This implies that different transcriptional start sites are being used in a cell-specific manner. Thus cell-specific transcription factors must be involved in silencing or activating the corresponding transcription of $m C G \beta$ in the pituitary and placenta. Analysing the promoter structure of the $m C G \beta$ gene should give insight into a promoter version that resembles an ambiguous form in terms of cell specificity when compared with other $C G \beta$ promoters, in which expression of CG $\beta$ mRNA is restricted to the trophoblasts.

The Western blot experiments proved that $\mathrm{mCG}$ is expressed in the pituitary of the marmoset monkey. Detection of the mGG $\beta$ subunit is specific because a positive control, $\mathrm{CHO}$ cells stably expressing the recombinant $\mathrm{mGG}$, gave 


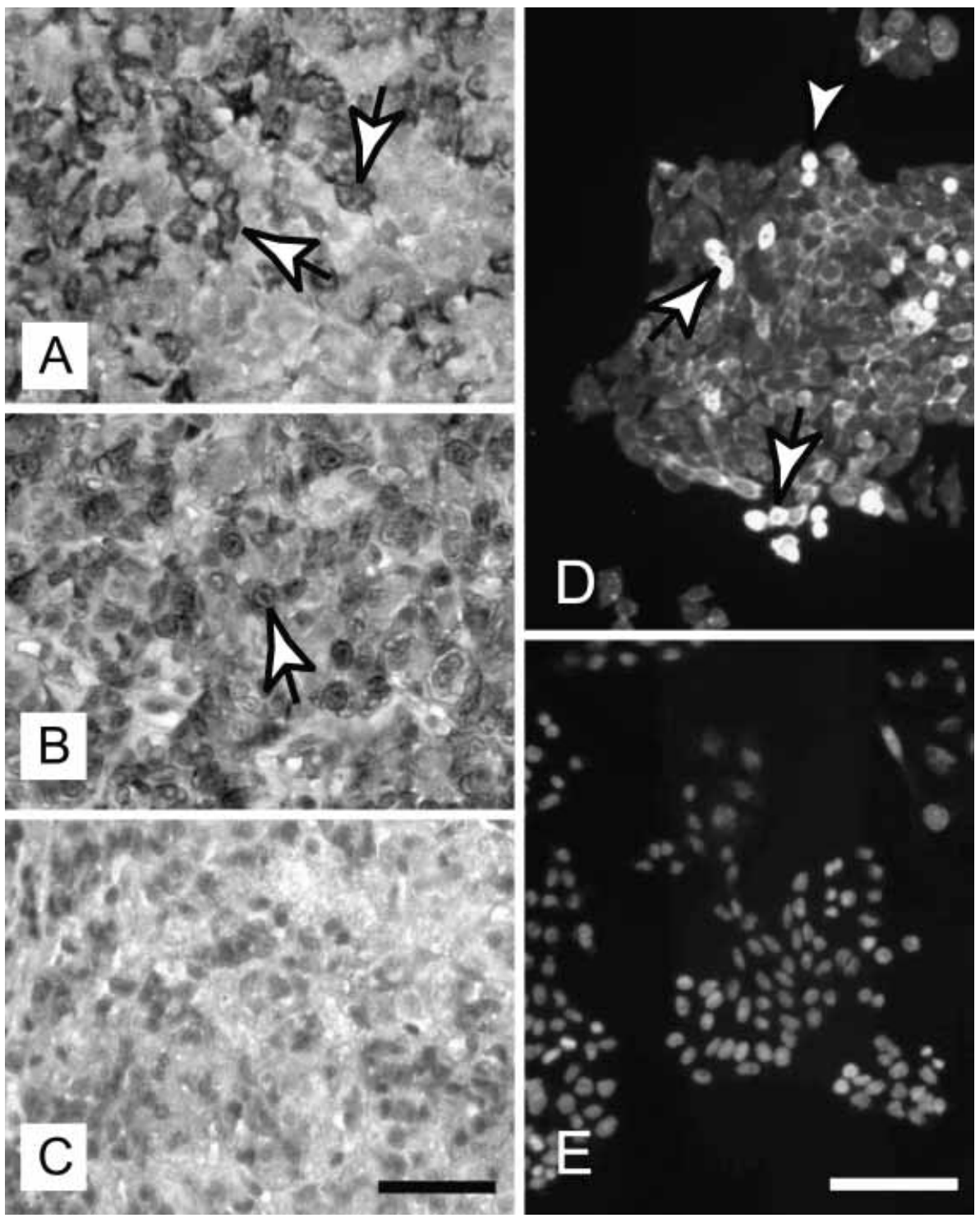

Figure 7 Immunocytochemistry of $\mathrm{mCG}$ in the marmoset pituitary. CG-positive cells and FSH-positive cells were stained with diaminobenzidine using an anti-human chorionic gonadotrophin antibody (A) or an anti-human FSH antibody (B) in marmoset pituitary. Negative controls $(C)$ were generated by omitting the primary antibodies. (D) CHO cells stained positive for MCG; the nuclei are counterstained with DAPI. (E) Negative control: staining was absent when the first antibody was omitted. Scale bar represents $50 \mu \mathrm{m}$.

comparable signals whereas pituitaries from rat and cynomolgus monkey, only expressing LH in the pituitary, remained without any detectable signal (Amato et al. 1998). The observed slight shift in size in the marmoset pituitary could be the result of a different glycosylation pattern, known from other recombinant gonadotrophins. The molecular mass obtained is in agreement with the findings of previous studies (Simula et al. 1995).

Immunocytochemical data showed that both CG and FSH were expressed in gonadotrophic cells of the marmoset pituitary and that, as in other species, both gonadotrophins are partly co-localized in the same cells (Wittkowski 1971, Watanabe et al. 1998, 


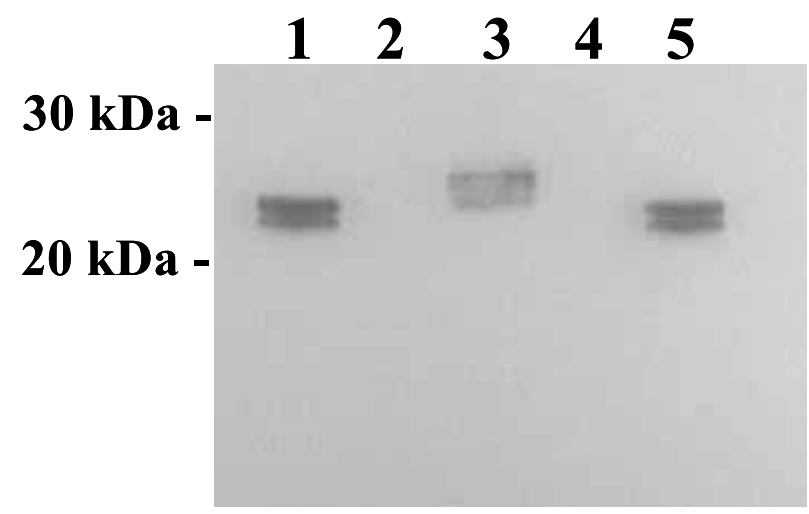

Figure 8 Western blot for mCG. Protein extracts from a $\mathrm{CHO}$ cell line stably expressing recombinant $\mathrm{mCG}$ (lanes 1 and 5) or pituitaries from rat (lane 2), marmoset monkey (lane 3) and cynomolgus monkey (lane 4) were subjected to SDS-PAGE and blotted. Using a specific mCG polyclonal antibody, duplicate bands were detectable in the protein extracts of the $\mathrm{CHO}$ cells expressing recombinant mCG (approx. $25 \mathrm{kDa}$ ) and the marmoset pituitary (approx. $27 \mathrm{kDa}$ ). No such bands could be detected in the pituitaries of the cynomolgus monkey or rat.

Crawford \& McNeilly 2002, Meeran et al. 2003). The pattern of localisation of $\mathrm{mCG}$ and $\mathrm{FSH}$ and the numbers of positive cells resembled previously published distributions for LH and FSH (Tixier et al. 1975, Newman et al. 1989, Sharpe et al. 2002). This suggests that gonadotropin-releasing hormone also regulates synthesis and secretion of both $\mathrm{CG}$ and FSH from the pituitary gland in the marmoset monkey. Normally, pulsatile LH secretion is important for normal steroidogenesis, which can be supported optimally with a short gonadotrophin half-life. Because of the presence of the CTP and a different pattern of glycosylation, placental CG has a longer half-life, which is optimal for maintaining pregnancy by rescuing progesterone production by the corpus luteum. In most species, CG $\beta$ shows four $\mathrm{O}$-glycosylations in its CTP that are responsible for the extension of the half-life of this gonadotrophin (Pierce \& Parsons 1981, Chen et al. 1982, Matzuk et al. 1990, Wilson et al. 1990). mCG $\beta$ lacks one $\mathcal{N}$-glycosylation at Asn 13 and two $O$-glycosylations in its terminal region, but has gained an additional $\mathcal{N}$-glycosylation site at Asn 126 (Fig. 3) (Simula et al. 1995). Subsequent biochemical studies indicated two $\mathcal{N}$-linked and one $O$-linked oligosaccharides in the secreted protein (Amato et al. 1998). In addition, the pattern of glycosylation of pituitary hCG is different from that of placenta hCG, because of the presence of sulphate and sialic acid residues, which renders the molecule more similar to LH (Birken et al. 1996). The pituitary gland is known to express the relevant glycosylation enzymes, which are not expressed in the placenta. In addition, the terminal sulphate residues on LH are recognized by the mannose/GalNAc-4-SO(4) receptor located in hepatic endothelial cells, which sequester and metabolise the hormone, contributing to the pulsatile pattern of the presence of $\mathrm{LH}$ in blood (Baenziger et al. 2003). If this also occurs in the marmoset, this could result in a shorter half-life of pituitary $\mathrm{mCG}$, resulting in pulsatility. We suggest that the data reported by Hodges (1978) and O'Byrne et al. (1988), showing that mLH secretion is pulsatile with a peak every hour, should be reinterpreted as showing that $\mathrm{CG}$ is secreted in a pulsatile fashion from the marmoset pituitary. These authors measured LH by Leydig cell bioassay, which cannot distinguish between LH and $\mathrm{CG}$, and by RIA using an anti-ovine rabbit LH $610 \mathrm{~V}$ antiserum, which is not specific for mLH. As the pattern of glycosylation of $\mathrm{LH}$ is essential to maintain pulsatile concentrations in serum (Baenziger 2003), these data suggest that glycosylation of pituitary $\mathrm{CG}$ is compatible with a short-lived gonadotrophin. Further studies are required to investigate whether the pattern of glycosylation of placental CG is different from that of pituitary $\mathrm{CG}$.

Both hLH and hCG can activate the marmoset LHR, as demonstrated by in vitro experiments in transiently transfected COS7-cells (unpublished data) and by isolated and perfused corpora lutea (Einspanier \& Hodges 1994). It is unclear whether genuine $\mathrm{mLH}$ would act on its own receptor, but most probably it would, even if it is expected that mLH would show lower bioactivity than CG. In fact, we have shown that $\mathrm{mCG}$ lacking CTP is less bioactive than complete $\mathrm{mCG}$, suggesting that the CTP of $C G \beta$ can compensate for the loss of exon 10 of the LHR in receptor activation ( $\mathrm{T}$ Müller, $\mathrm{J}$ Gromoll, AP Simula, R Norman, R SandhoweKlaverkamp and M Simoni, Unpublished Observation).

In summary, the surprising fact that $L H \beta$ is a pseudogene in the marmoset monkey is a peculiar finding in the LH-CG-LHR system of this species and may also be true in other New World monkeys that also possess the LH receptor type II lacking 
exon 10 (Gromoll et al. 2003). In view of recent data reported by Maston \& Ruvolo (2002), there are two possible explanations for the loss of expression of $L H \beta$. For both hypotheses, the first steps are identical: the $L H \beta$ gene duplicates and mutates, giving rise to the $C G \beta$ gene originally expressed in pituitary and placenta, and $C G \beta$ acquires expression in the placenta of species with a hemochoral placenta (Tarsiers). At this point, two evolutionary pathways are possible. The first is that a mutation or another genomic event (insertion of a retrotransposon, indicated by the unusually large DNA fragment inserted between the $m L H \beta$ and $m C G \beta$ genes) disrupts the regulatory sequence of the $L H \beta$ gene in Platyrrhini; $C G \beta$, however, compensates for loss of $L H \beta$ expression. Then the expression of exon 10 of the LHR, redundant for CG $\beta$ action, is lost as a result of mutation(s) in the New World monkeys; the mutation is irrelevant for receptor function, driven by CG $\beta$. Alternatively, a mutation or another genomic event disrupts exon 10 of the LHR in the Platyrrhini lineage and, because of the pituitary expression of $\mathrm{CG}$, which is more bioactive on the LHR lacking exon 10, expression of $L H \beta$ is lost. As a consequence the 'luteinising' function is maintained by CG. Finally, the glycosylation machinery of the pituitary gland, different from that of the placenta, could result in a pattern of glycosylation compatible with short hormone half-life and pulsatility.

Our findings strongly suggest that $L H \beta$ is a pseudogene in the marmoset monkey, and that all previous studies dealing with $\mathrm{LH}$ secretion and serum concentration in this species (Rosenbusch et al. 1994, O'Byrne et al. 1988) should be reconsidered from the viewpoint that $\mathrm{CG}$, and not $\mathrm{LH}$, is produced by the pituitary gland.

\section{Acknowledgements}

The technical assistance of $\mathrm{R}$ SandhoweKlaverkamp, N Terwort and I Upmann is gratefully acknowledged. We are grateful to Prof. E Nieschlag for his constant, stimulating support and to $\mathrm{T}$ G Cooper $\mathrm{PhD}$, and $\mathrm{S}$ Nieschlag MA, for language editing of the manuscript. The work was supported by the German Research Foundation (DFG, GR 1547/2-1) and IMF grant SI520003.
Dr R Chandolia was the recipient of a German Academic Exchange Service (DAAD) fellowship.

\section{References}

Amato F, Simula AP, Gameau LJ \& Norman RJ 1998 Expression, characterization and immunoassay of recombinant marmoset chorionic gonadotrophin dimer and $\beta$-subunit. Fournal of Endocrinology 159 141-151.

Baenziger JU 2003 Glycoprotein hormone GalNAc-4sulphotransferase. Biochemical Society Transactions 31 326-330.

Birken S, Maydelman Y, Gawinowicz MA, Pound A, Liu Y \& Hartree AS 1996 Isolation and characterization of human pituitary chorionic gonadotropin. Endocrinology 137 1402-1411.

Chen HC, Shimohigashi Y, Dufau ML \& Catt KJ 1982

Characterization and biological properties of chemically deglycosylated human chorionic gonadotrophin. Fournal of Biological Chemistry 257 14446-14452.

Crawford JL \& McNeilly AS 2002 Co-localisation of gonadotrophins and granins in gonadotrophs at different stages of the oestrous cycle in sheep. Fournal of Endocrinology 174 179-194.

Dufau ML 1998 The luteinising hormone receptor. Annual Revieres in Physiology 60 461-496.

Einspanier A \& Hodges JK 1994 LH- and chorionic gonadotrophinstimulated progesterone release in vitro by intact luteal tissue of the marmoset monkey (Callithrix jacchus). Fournal of Endocrinology 141 403-409.

Fiddes JC \& Goodman HM 1980 The cDNA for the beta-subunit of human chorionic gonadotrophin suggests evolution of a gene by read through into the $3^{\prime}$-untranslated region. Nature $286684-687$.

Gromoll J, Weinbauer GF, Simoni M \& Nieschlag E 1993 Effects of antiandrogens and ethane dimethane sulphonate (EDS) on gene expression, free subunits, bioactivity and secretion of pituitary gonadotrophins in male rats. Molecular and Cellular Endocrinology 91 119-125.

Gromoll J, Eiholzer U, Nieschlag E \& Simoni M 2000 Male hypogonadism caused by a homozygous deletion of exon 10 of the luteinising hormone receptor: differential action of human chorionic gonadotrophin and LH. Fournal of Clinical Endocrinology and Metabolism 85 2281-2286.

Gromoll J, Wistuba J, Terwort N, Godmann M, Muller T \& Simoni M 2003 A new subclass of the luteinising hormone/chorionic gonadotrophin receptor lacking exon 10 messenger RNA in the New World Monkey (Platyrrhini) lineage. Biology of Reproduction 69 75-80.

Hobson BM \& Wide L 1981 The similarity of chorionic gonadotrophin and its subunits in term placentae from man, apes, Old and New World Monkeys and a Prosimian. Folia Primatologica 35 35-64.

Hodges JK 1978 Effects of gonadectomy and oestradiol treatment on plasma luteinising hormone concentrations in the marmoset monkey, Callithrix jacchus. Fournal of Endocrinology 76 271-281.

Hollenberg AN, Pestell RG, Albanese G, Boers ME \& Jameson JL 1994 Multiple promoter elements in the human chorionic gonadotrophin $\beta$ subunit genes distinguish their expression from the luteinising hormone $\beta$ gene. Molecular and Cellular Endocrinology $106111-119$.

Jameson L, Chin WW, Hollenberg AN, Chang AS \& Habener JF 1984 The gene encoding the beta-subunit of rat luteinising hormone. Analysis of gene structure and evolution of nucleotide sequence. Fournal of Biological Chemistry 259 15474-15480.

Kumar S \& Hedges SB 1998 A molecular timescale for vertebrate evolution. Nature 392 917-920.

Lundwall A \& Olsson YM 2001 Semenogelin II gene is replaced by a truncated LINE1 repeat in the cotton-top tamarin. Biology of Reproduction 65 420-425. 
Maston GA \& Ruvolo M 2002 Chorionic gonadotrophin has a recent origin within primates and an evolutionary history of selection. Molecular Biology of Evolution 19 320-335.

Matzuk MM, Hsueh AJW, Lapolt P, Tsafiri A, Keene JL \& Boime I 1990 The biological role of the carboxyterminal extension of human chorionic gonadotrophin. Endocrinology 126 376-383.

Meeran D, Urbanski HF, Gregory SJ, Townsend J \& Tortonese DJ 2003 Developmental changes in the hormonal identity of gonadotroph cells in the rhesus monkey pituitary gland. Fournal of Clinical Endocrinology and Metabolism 88 2934-2942.

Müller T, Gromoll J \& Simoni M 2003 Absence of exon 10 of the human luteinising hormone (LH) receptor impairs $\mathrm{LH}$, but not human chorionic gonadotrophin action. Fournal of Clinical Endocrinology and Metabolism $882242-2249$.

Newman GR, Jasani B \& Williams ED 1989 Multiple hormone storage by cells of the human pituitary. Fournal of Histochemical Cytochemistry 37 1183-1192.

O'Byrne KT, Lunn SF \& Dixson AF 1988 Effects of acute stress on the patterns of LH secretion in the common marmoset (Callithrix jacchus). Fournal of Endocrinology 118 259-264.

Pierce JG \& Parsons TF 1981 Glycoprotein hormones: structure and function. Annual Reviewes in Biochemistry 50 465-495.

Policastro P, Ovitt CE, Hoshina M, Fukuoka H, Boothby MR \& Boime I 1983 The $\beta$ subunit of human chorionic gonadotrophin is encoded by multiple genes. Fournal of Biological Chemistry $\mathbf{2 5 8}$ 11492-11499.

Rosenbusch J, Bellmann A \& Hodges JK 1994 Molecular mass and isoelectric properties of pituitary and urinary gonadotrophins in callitrichid primates. Fournal for Reproduction and Fertility 102 493-500.

Saunders PTK, Summers PM \& Hearn JP 1987 Partial purification and characterization of chorionic gonadotrophin in plasma and in culture medium of trophoblast cells from the marmoset monkey (Callithrix jacchus). Fournal for Reproduction and Fertility 80 463-472.

Schmidt A, Gromoll J, Weinbauer GF, Galla H-J, Chappel S \& Simoni M 1999 Cloning and expression of cynomolgus monkey (Macaca fascicularis) gonadotrophins luteinising hormone and follicle-stimulating hormone and identification of two polymorphic sites in the luteinising hormone $\beta$ subunit. Molecular and Cellular Endocrinology 156 73-83.

Sharpe RM, Bronwen M, Morris K, Greig I, McKinnell C, McNeilly AS \& Walker M 2002 Infant feeding with soy formula milk: effects on the testis and on blood testosterone levels in marmoset monkeys during the period of neonatal testicular activity. Human Reproduction 17 1692-1703.

Sherman GB, Wolfe MW, Farmerie TA, Clay CM, Threadgill DS, Sharp DC \& Nilson JH 1992 A single gene encodes the $\beta$-subunits of equine luteinising hormone and chorionic gonadotrophin. Molecular Endocrinology 6 951-959.

Sherman GB, Heilman DF, Hoss AJ, Bunick D \& Lund LA 2001 Messenger RNAs encoding the $\beta$ subunits of guinea pig (Cavia porcellus) luteinising hormone (gpLH) and putative chorionic gonadotrophin (gpCG) are transcribed from a single-copy gpLH/CG $\beta$ gene. Fournal of Molecular Endocrinology 26 267-280.

Simoni M, Weinbauer GF, Gromoll J \& Nieschlag E 1999 Role of FSH in male gonadal function. Annales d'Endocrinologie 60 102-106.

Simula AP, Amato F, Faast R, Lopata A, Berka J \& Norman RJ 1995 Luteinising hormone/chorionic gonadotrophin bioactivity in the common marmoset (Callithrix jacchus) is due to a chorionic gonadotrophin molecule with a structure intermediate between human chorionic gonadotrophin and human luteinising hormone. Biology of Reproduction 53 380-389.

Smith D, Trennery P, Farningham D \& Klapwijk J 2001 The selection of marmoset monkeys (Callithrix jacchus) in pharmaceutical toxicology. Laboratory Animals 35 117-130.

Talmadge K, Vamvakopoulos NC \& Fiddes JC 1984 Evolution of the genes for the beta subunits of human chorionic gonadotrophin and luteinising hormone. Nature 307 37-40.

Tixier-Vidal A, Tougard G, Kerdelhue B \& Jutisz M 1975 Light and electron microscopic studies on immunocytochemical localization of gonadotropic hormones in the rat pituitary gland with antisera against FSH, LH and LH $\alpha$ and LH $\beta$. Annals of the New York Academy of Sciences 254 433-461.

Watanabe T, Azuma T, Banno T, Jeziorowski T, Ohsawa Y, Waguri S, Grube D \& Uchiyama Y 1998 Immunocytochemical localization of chromogranin A and secretogranin II in female rat gonadotropes. Archives of Histological Cytology 61 99-113.

Weinbauer GF, Gromoll J, Simoni M \& Nieschlag E 2000 Hormonal control of testicular function. In: Andrology, edn 2, pp 23-57. Eds E Nieschlag \& HM Behre. Berlin: Springer Verlag.

Wilson CA, Leigh AJ \& Chapman AJ 1990 Gonadotrophin glycosylation and function. Fournal of Endocrinology 125 3-14.

Wittkowski W 1971 Glandular cell types and localization of hormones in the pituitary gland anterior lobe. Deutsche Medizinische Wochenschrift 96 1225-1238.

Zhang FP, Rannikko AS, Manna PR, Fraser HM \& Huhtaniemi IT 1997 Cloning and functional expression of the luteinising hormone receptor complementary deoxyribonucleic acid from the marmoset monkey testis: absence of sequences encoding exon 10 in other species. Endocrinology 138 2481-2490.

Zhang FP, Kero J \& Huhtaniemi I 1998 The unique exon 10 of the human luteinising hormone receptor is necessary for expression of the receptor protein at the plasma membrane in the human luteinising hormone receptor, but deleterious when inserted into the human follicle-stimulating hormone receptor. Molecular and Cellular Endocrinology 142 165-174.

Zuehlke U \& Weinbauer G 2003 The common marmoset (Callithrix jacchus) as a model in toxicology. Toxicological Pathology 31 123-127.

Received in final form 16 October 2003.

Accepted 10 November 2003.

Made available online as an

Accepted Preprint 18 November 2003. 